\title{
Effectiveness of Visual Scanning Training at Reducing Left Neglect: A Systematic Review
}

\author{
Barbara Jean Baker, Anna Marie Bennison, Kelly Jo Rohde, Lindsey Danielle Timmer and Bonni Lynn Kinne* \\ Department of Physical Therapy, Grand Valley State University, USA
}

Submission: October 23, 2018; Published: March 15, 2019

*Corresponding author: Bonni Kinne, Department of Physical Therapy, Grand Valley State University, 301 Michigan Street NE, Grand Rapids, MI 49503, USA

\begin{abstract}
Introduction: One of the most common cognitive issues associated with a cerebrovascular accident (CVA) is an attention deficit known as hemispatial neglect. Once neglect has been diagnosed, therapists have a number of different interventions from which to choose. One of the earliest interventions still in use today is visual scanning training (VST). The purpose of this systematic review was to evaluate the effectiveness of VST at reducing the effects of left neglect caused by a right-sided CVA.

Methods: CINAHL Complete, ProQuest Medical Library, and PubMed were the databases used to search the terms "visual scanning" AND "neglect" AND "randomized".

Results: The use of VST with conventional therapy was better than the provision of no treatment or the use of conventional therapy alone. VST was better at reducing the effects of left neglect than was mental practice training. Although VST was generally less effective at reducing left neglect when compared to several other interventions, participants who received VST still demonstrated statistically significant improvements.

Discussion: VST is generally an effective intervention for reducing the effects of left neglect, especially when it is performed as originally intended. The positive impacts of VST may not be apparent until the intervention has been delivered over a prolonged period of time. The effectiveness of VST appears to be enhanced when it is used in combination with conventional therapy or with other interventions.
\end{abstract}

Conclusion: VST is an acceptable option when treating individuals with left neglect caused by a right-sided CVA.

Keywords: Cerebrovascular accident, Neglect, Visual scanning training

\section{Introduction}

A cerebrovascular accident (CVA) may be defined as "a sustained neurologic deficit arising from abrupt focal vascular injury... within the brain parenchyma" [1]. (p205) CVAs have affected over 7 million individuals in the United States alone, and almost 800,000 Americans experience a CVA on an annual basis [2]. CVAs affect African Americans, Native Americans, and multiracial individuals more than they do members of other ethnic groups [2-3]. In addition, more females experience CVAs than do males. Although a CVA may occur at any age, CVAs more often affect older adults than they do younger individuals [1-3]. The leading risk factors associated with a CVA include hypercholesterolemia, hypertension, obesity, diabetes mellitus, and the use of tobacco products [4]. Approximately 90 percent of all CVAs are considered ischemic strokes (caused by the blockage of a blood vessel), and approximately 10 percent of all CVAs are considered hemorrhagic strokes (caused by the leakage of a blood vessel) [2,5]. CVAs frequently result in cognitive issues such as deficits in attention, emotion, language, memory, movement, sensation, and executive functions [1]. One of the most common cognitive issues associated with a CVA is an attention deficit known as hemispatial neglect $[1,6]$.

Hemispatial neglect is a situation in which individuals "fail to orientate themselves towards or to detect items on their contralesional side..., even though they are not blind to stimuli on that side" [7]. (p26) Up to two-thirds of individuals who experience a CVA demonstrate neglect in the acute stages of their recovery. If an individual's neglect continues on a long-term basis, functional independence is negatively affected $[6,8]$. Right neglect results from a left-sided CVA, and left neglect results from a right-sided CVA [8]. There is a fairly equal distribution of right neglect and left neglect shortly after a CVA has occurred [1]. However, the symptoms associated with left neglect tend to 
be more persistent [1,6-8]. CVAs that involve the middle cerebral artery are most likely to cause neglect [7-8]. Although damage in the region of the temporoparietal junction was originally thought to be the primary source of neglect, the most recent theory is that neglect results from damage to multiple areas of the brain [6-8]. In order to detect the presence of neglect, therapists may need to utilize several different tests [1,8]. Azouvi, et al. [9] found that over 70 percent of all individuals with neglect could be properly diagnosed by utilizing a combination of a cancellation task, a clock-drawing task, and an object-copying task; and Malhotra et al.[10] found that over 90 percent of all individuals with neglect could be properly diagnosed by including the following three tasks in the test battery: cancellation, line bisection, and naming 10 objects around the room. Once neglect has been diagnosed, therapists have a number of different interventions from which to choose [6,8]. One of the earliest interventions still in use today is visual scanning training (VST) [8].

VST was first developed as an intervention for neglect in 1977 [11]. According to Weinberg et al., [12]. "if [an individual] could be taught consciously to scan the environment in order to compensate for neglect, improvement could be demonstrated in... a variety of seemingly disparate visual tasks". (p480) Diller and Weinberg [11] stated that VST is most successful when the initial step of the process focuses on making individuals aware of their neglect. After this objective has been accomplished, neglect may be overcome by

a. Providing individuals with a relevant task that encourages them to rotate their head and neck in the direction of their neglect,

b. Cuing individuals to begin the task by visualizing the object that is furthest into their area of neglect (anchoring),

c. Helping individuals perform the task more accurately by increasing the distance between each of the objects (density),

d. Instructing individuals to execute the task more slowly by counting the objects out loud (pacing), and (e) providing individuals with positive, specific feedback immediately after they have completed the task.

In their 1977 study, Diller and Weinberg [11] discovered that VST was a generally effective intervention for neglect when it was used in the treatment plan of two patients. Since that time, several other interventions have been developed. In addition, a number of randomized controlled trials have compared the effectiveness of VST with these other interventions.

Two previous systematic reviews attempted to determine which interventions were most capable of reducing the effects of hemispatial neglect [13-14]. In 2006, Luaute, et al. [13] ranked 18 different interventions from best, Grade A, to worst, Grade $\mathrm{E}$ (the authors also included a non-conclusive category). This systematic review classified VST as a Grade B intervention based upon the existing evidence at the time. However, the study was published over 10 years ago. In 2015, Klinke, et al. [14] ranked 11 different interventions from best, Grade A, to worst, Grade D. Although this systematic review classified VST as a Grade D intervention, the study only included one randomized controlled trial related to the topic. Therefore, because the information described above points to a gap in the literature, the purpose of this current systematic review was to evaluate the effectiveness of VST at reducing the effects of left neglect caused by a rightsided CVA.

\section{Methods}

\section{Databases and Search Terms}

CINAHL Complete, ProQuest Medical Library, and PubMed were the databases used to search the terms "visual scanning" AND "neglect" AND "randomized". Other than the Luaute et al. [13] study and the Klinke, et al. [14] study previously described, the Cochrane Library did not contain any other relevant systematic reviews. Because this systematic review only included studies published in English, there was the potential that a language bias was created.

\section{Inclusion and Exclusion Criteria}

The following inclusion criteria were used for this systematic review:

a. adults, 18 years of age and older, diagnosed with left neglect due to a CVA;

b. an intervention group that received VST;

c. a comparison group that received other interventions or no intervention;

d. reliable and valid outcome measures that evaluated changes in neglect; and

e. randomized controlled trials.

The following exclusion criteria were used for this systematic review:

a. adults without left neglect;

b. adults with left neglect due to a neurologic disorder other than a CVA,

c. children, under 18 years of age, diagnosed with left neglect;

d. an intervention group that did not receive VST; and

e. the use of VST in combination with other interventions.

\section{Evidence Level}

The Oxford Centre for Evidence-Based Medicine 2011 Levels of Evidence was used to establish the evidence level of each study included in this systematic review [15] (Table 1). The highest level of evidence is level one, whereas the lowest level 


\section{Open Access Journal of Neurology \& Neurosurgery}

of evidence is level five. The included studies were individually assessed by all five authors, thus reducing the risk of bias. If the authors disagreed about the evidence level of a particular study, a discussion was undertaken to reach a common conclusion.

Table 1: Evidence Level (EL) Overview.

\begin{tabular}{|c|c|}
\hline Hierarchy & EL Criteria \\
\hline 1 & systematic reviews of randomized trials or $n$-of- 1 trials \\
\hline 2 & $\begin{array}{l}\text { randomized trials or observational studies with } \\
\text { dramatic effect }\end{array}$ \\
\hline 3 & non-randomized controlled cohort or follow-up studies \\
\hline 4 & $\begin{array}{l}\text { case-series, case-control studies, or historically } \\
\text { controlled studies }\end{array}$ \\
\hline 5 & mechanism-based reasoning \\
\hline
\end{tabular}

\section{Methodological Rigor}

Table 2: Methodological Rigor (MR) Overview.

\begin{tabular}{|c|c|}
\hline Item & MR Criteria \\
\hline 1 & random allocation of subjects \\
\hline 2 & concealed allocation of subjects \\
\hline 3 & similar groups at baseline \\
\hline 4 & blinding of all subjects \\
\hline 5 & blinding of all therapists \\
\hline 6 & blinding of all assessors \\
\hline 7 & key outcome measures obtained from 85\% of subjects \\
\hline 8 & treatment received as allocated or "intention to treat" \\
\hline 9 & $\begin{array}{c}\text { between-group statistical comparisons reported for one key } \\
\text { outcome }\end{array}$ \\
\hline 10 & $\begin{array}{c}\text { point measures/variability measures provided for one key } \\
\text { outcome }\end{array}$ \\
\hline
\end{tabular}

The PEDro scale was used to establish the methodological rigor of each study included in this systematic review [16] (Table 2). The scale includes 10 criteria that measure internal validity. Therefore, each research article ultimately receives a rating of 0 (the lowest methodological rigor) to 10 (the highest methodological rigor). The included studies were individually assessed by all five authors, thus reducing the risk of bias. If the authors disagreed about the methodological rigor of a particular study, a discussion was undertaken to reach a common conclusion.

\section{Results}

\section{Search Strategy}

Three electronic databases revealed 1069 article, and two additional articles were discovered through alternate sources. Duplicates were eliminated, and 1028 articles were screened by title and abstract as displayed in the PRISMA 2009 flow diagram (Figure 1) [17]. After the 1028 articles were screened, 1016 articles were eliminated, and 12 articles were evaluated by a full-text assessment to determine their eligibility based on the inclusion and exclusion criteria. Eight articles [12,18-24] were found to be eligible and were used in this systematic review.

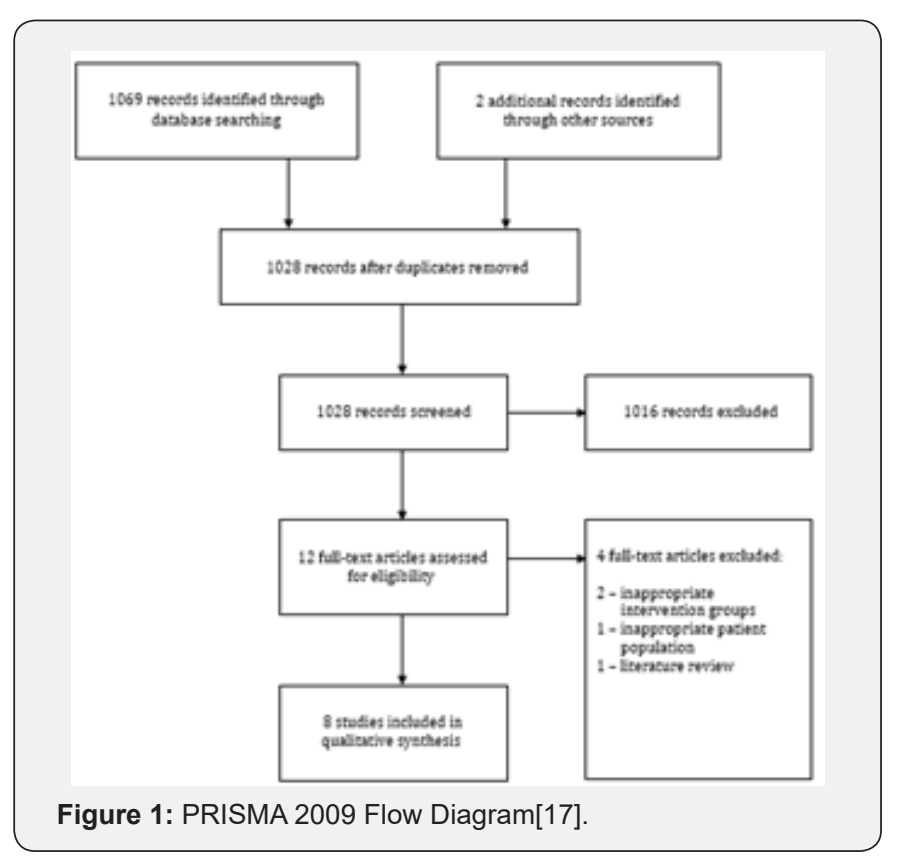

\section{Evidence Level}

Based on the Oxford Centre for Evidence-Based Medicine 2011 Levels of Evidence [15] all eight articles were considered level 2 evidence because they were randomized controlled trials [12,18-24] (Table 3).

Table 3: Evidence Level (EL) Results.

\begin{tabular}{|c|c|c|}
\hline Author \& Date & Hierarchy & EL Score \\
\hline Chan \& Man [18] & $\begin{array}{c}\text { randomized } \\
\text { controlled trial }\end{array}$ & 2 \\
\hline Ferreira, et al. [19] & $\begin{array}{c}\text { randomized } \\
\text { controlled trial }\end{array}$ & 2 \\
\hline Ianes, et al. [20] & $\begin{array}{c}\text { randomized } \\
\text { controlled trial }\end{array}$ & 2 \\
\hline Kerkhoff, et al. [21] & $\begin{array}{c}\text { randomized } \\
\text { controlled trial }\end{array}$ & 2 \\
\hline Kerkhoff, et al. [22] & $\begin{array}{c}\text { randomized } \\
\text { controlled trial }\end{array}$ & 2 \\
\hline Kerkhoff, et al. [23] & $\begin{array}{c}\text { randomized } \\
\text { controlled trial }\end{array}$ & 2 \\
\hline Luukkainen-Markkula, et al. [24] & $\begin{array}{c}\text { randomized } \\
\text { controlled trial }\end{array}$ & 2 \\
\hline Weinberg, et al. [12] & $\begin{array}{c}\text { randomized } \\
\text { controlled trial }\end{array}$ & 2 \\
\hline
\end{tabular}

\section{Methodological Rigor}

Based on the PEDro scale [16], all eight studies received a methodological rigor score between $6 / 10$ and 8/10 [12,18-24] (Table 4).

\section{Summary of Studies}

Chan and Man [18] examined 40 participants with left neglect caused by a right-sided CVA and randomized them into two groups. Group one consisted of 20 participants who received VST, and group two consisted of 20 participants 
who received conventional therapy and served as the control group. Group one followed a four-week protocol (12 45-minute sessions) that included four different visual scanning tasks, and this group underwent evaluations pre-treatment and posttreatment. Group two underwent a baseline evaluation and an evaluation four weeks later. Neglect outcomes were measured by the Behavioral Inattention Test (BIT) and the Catherine Bergego Scale (CBS) [26]. The BIT [25] is an instrument that measures nine behavioral activities (such as card sorting) and six conventional activities (such as representational drawing). The CBS is an instrument that measures 10 self-care activities (such as transfers) [26]. The results of this study can be found in Table 5.

Table 4: Methodological Rigor (MR) Results

\begin{tabular}{|c|c|c|c|c|c|c|c|c|c|c|c|}
\hline Author \& Date & 1 & 2 & 3 & 4 & 5 & 6 & 7 & 8 & 9 & 10 & $\begin{array}{l}\text { MR } \\
\text { Score }\end{array}$ \\
\hline $\begin{array}{c}\text { Chan \& Man } \\
{[18]}\end{array}$ & $Y$ & $\mathrm{~N}$ & $\mathrm{~N}$ & $\mathrm{~N}$ & $\mathrm{~N}$ & $Y$ & Y & Y & $Y$ & $Y$ & $6 / 10$ \\
\hline $\begin{array}{c}\text { Ferreira, et al. } \\
{[19]}\end{array}$ & $Y$ & $\mathrm{~N}$ & $Y$ & $\mathrm{~N}$ & $\mathrm{~N}$ & Y & Y & Y & $Y$ & $Y$ & $7 / 10$ \\
\hline Ianes, et al. [20] & Y & Y & Y & $\mathrm{N}$ & $\mathrm{N}$ & Y & Y & Y & Y & Y & $8 / 10$ \\
\hline $\begin{array}{c}\text { Kerkhoff, et al. } \\
{[21]}\end{array}$ & $Y$ & Y & $Y$ & $\mathrm{~N}$ & $\mathrm{~N}$ & Y & Y & Y & Y & Y & $8 / 10$ \\
\hline $\begin{array}{c}\text { Kerkhoff, et al. } \\
\text { [22] }\end{array}$ & $Y$ & Y & $Y$ & $\mathrm{~N}$ & $\mathrm{~N}$ & $\mathrm{~N}$ & Y & $\mathrm{N}$ & Y & Y & $6 / 10$ \\
\hline $\begin{array}{c}\text { Kerkhoff, et al. } \\
\text { [23] }\end{array}$ & Y & Y & Y & $\mathrm{N}$ & $\mathrm{N}$ & $\mathrm{N}$ & Y & Y & $Y$ & Y & $7 / 10$ \\
\hline $\begin{array}{l}\text { Luukkainen- } \\
\text { Markkula, et al. } \\
{[24]}\end{array}$ & Y & Y & Y & $\mathrm{N}$ & $\mathrm{N}$ & $\mathrm{N}$ & Y & Y & Y & Y & $7 / 10$ \\
\hline $\begin{array}{c}\text { Weinberg, et al. } \\
{[12]}\end{array}$ & $Y$ & $\mathrm{~N}$ & $Y$ & $\mathrm{~N}$ & $\mathrm{~N}$ & $Y$ & Y & Y & $Y$ & $Y$ & $7 / 10$ \\
\hline
\end{tabular}

$1=$ random allocation of subjects; 2 = concealed allocation of subjects; $3=$ similar groups at baseline; $4=$ blinding of all subjects; $5=$ blinding of all therapists; 6 = blinding of all assessors; $7=$ key outcome measures obtained from $85 \%$ of subjects; $8=$ treatment received as allocated or "intention to treat"; $9=$ between-group statistical comparisons reported for one key outcome; $10=$ point measures/ variability measures provided for one key outcome.

Ferreira, et al. [19] examined 10 participants with left neglect caused by a right-sided CVA and randomized them into two groups. Group one consisted of five participants who received VST, and group two consisted of five participants who received mental practice training. An additional five participants, who were unwilling to undergo an intervention, received no treatment and served as the control group. Both training groups followed a five-week protocol (10 one-hour sessions). Group one's protocol included two tasks focused on extrapersonal space and two tasks focused on peripersonal neglect, and group two's protocol included two tasks focused on motor imagery and two tasks focused on visual imagery. Both training groups underwent evaluations pre-treatment, post-treatment, and three months following treatment. The control group underwent a baseline evaluation and an evaluation two months later. Neglect outcomes were measured by the BIT [25] as previously discussed in the Chan and Man [18] study. The results of this study can be found in Table 5 .

Ianes, et al. [20] examined 18 participants with left neglect caused by a right-sided CVA and randomized them into two groups. Group one consisted of eight participants who received VST, and group two consisted of 10 participants who received a right half-field patch. Group one followed an active protocol (40-minute sessions for 15 consecutive weekdays) that included several conventional VST tasks, and group two followed a passive protocol (eight-hour sessions for 15 consecutive days) that included donning a right half-field patch and performing no specific exercises. Both groups underwent evaluations pretreatment, post-treatment, and seven days following treatment. Neglect outcomes were measured by the Bells test, line bisection, and line crossing. The Bells test [27] requires the participant to circle 35 bells embedded within 280 distractors. The line bisection and line crossing activities are two of the conventional items contained in the BIT [25]. The results of this study can be found in Table 5 .

Kerkhoff, et al. [21]. examined 24 participants with left neglect caused by a right-sided CVA and randomized them into two groups. Group one consisted of 12 participants who received VST, and group two consisted of 12 participants who received smooth pursuit training. Both groups followed a one-month protocol (20 30-minute sessions). Group one's protocol included the visualization of static stimuli on a laptop screen, and group two's protocol included the visualization of dynamic stimuli on a laptop screen. Both groups underwent evaluations pretreatment, post-treatment, and two weeks following treatment. Neglect outcomes were measured by the Functional Neglect Index (FNI) and the Unawareness and Behavioral Neglect Index (UBNI). The FNI is an instrument that measures four functional activities (such as gaze orientation). The UBNI is an instrument that measures 10 self-care activities similar to those contained in the CBS [26]. The results of this study can be found in Table 5.

Kerkhoff, et al. [22] examined 45 participants with left neglect caused by a right-sided CVA and randomized them into two groups. Group one consisted of 21 participants who received VST, and group two consisted of 24 participants who received smooth pursuit training. Both groups followed a sevento nine-day protocol (five 50-minute sessions). Group one's protocol included the visualization of static stimuli on a laptop screen, and group two's protocol included the visualization of dynamic stimuli on a laptop screen. Both groups underwent evaluations pre-treatment, post-treatment, and two weeks following treatment. Neglect outcomes were measured by line bisection, numeral cancellation, and paragraph reading. Each of these activities is similar to an item contained in the BIT [25]. The results of this study can be found in Table 5 .

Kerkhoff, et al. [23] examined six participants with left neglect caused by a right-sided CVA and randomized them into two groups. Group one consisted of three participants who 


\section{Open Access Journal of Neurology \& Neurosurgery}

received VST, and group two consisted of three participants who received optokinetic stimulation training. Both groups followed a four-week protocol (20 50-minute sessions). Group one's protocol included the visualization of static stimuli on a computer screen, and group two's protocol included the visualization of dynamic stimuli on a computer screen. Both Table 5: Summary of Studies. groups underwent evaluations pre-treatment, post-treatment, and two months following treatment. Neglect outcomes were measured by line bisection, numeral cancellation, and paragraph reading as previously discussed in the Kerkhoff, et al. [22] study. The results of this study can be found in Table 5 .

\begin{tabular}{|c|c|c|c|c|}
\hline $\begin{array}{l}\text { Author \& } \\
\text { Date }\end{array}$ & EL \& MR & Population & Interventions & Outcomes \\
\hline \multirow[t]{3}{*}{$\begin{array}{l}\text { Chan \& Man } \\
\quad[18]\end{array}$} & $\begin{array}{c}E L=2 \\
M R=6 / 10\end{array}$ & $\begin{array}{l}\text { Group } 1 \\
\quad=20 \\
\text { participants }\end{array}$ & VST & $\begin{array}{l}\text { Group 1showed significant improvement pre-treatment to post-treatment on the BIT (p } \\
\qquad<0.001) \text { and on the CBS }(\mathrm{p}<0.001) .\end{array}$ \\
\hline & & $\begin{array}{l}\text { Group } 2 \\
\quad=20 \\
\text { participants }\end{array}$ & Control & $\begin{array}{l}\text { Group } 2 \text { showed significant improvement pre-treatment to post-treatment on the BIT } \\
\qquad(p=0.052) \text { and on the CBS }(p=0.004) .\end{array}$ \\
\hline & & & & $\begin{array}{l}\text { Group } 1 \text { showed significantly } \\
\text { greater improvement pre-treatment to }\end{array}$ \\
\hline \multirow[t]{12}{*}{$\begin{array}{l}\text { Ferreira et } \\
\text { al. [19] }\end{array}$} & $\begin{array}{c}\mathrm{EL}=2 \\
\mathrm{MR}=7 / 10\end{array}$ & $\begin{array}{l}\text { Group } 1=5 \\
\text { participants }\end{array}$ & VST & $\begin{array}{l}\text { The BIT score of Group } 1 \text { increased from } 102 \text { to } 126 \text { pre-treatment topost-treatment } \\
\text { (all five participants experienced a reduction in their neglect symptoms). }\end{array}$ \\
\hline & & $\begin{array}{l}\text { Group } 2=5 \\
\text { participants }\end{array}$ & $\begin{array}{l}\text { Mental Prac- } \\
\text { tice } \\
\text { Training }\end{array}$ & $\begin{array}{l}\text { The BIT score of Group } 2 \text { increased from } 91 \text { to } 97 \\
\text { pre-treatment to post-treatment } \\
\text { (four of the five participants } \\
\text { experienced a reduction in their neglect symptoms). }\end{array}$ \\
\hline & & $\begin{array}{l}\text { Group } 3=5 \\
\text { participants }\end{array}$ & Control & $\begin{array}{l}\text { The BIT score of Group } 3 \text { increased } \\
\text { from } 81 \text { to } 82 \text { pre-treatment to post-treatment. }\end{array}$ \\
\hline & & & & $\begin{array}{l}\text { No significant difference was } \\
\text { found between Group } 1 \text { and } \\
\text { Group } 2 \text { on the BIT pre-treatment } \\
\text { to post-treatment. }\end{array}$ \\
\hline & & & & $\begin{array}{c}\text { Group } 1 \text { showed significantly } \\
\text { greater improvement pre-treatment } \\
\text { to post-treatment on the } \\
\text { BIT }(p=0.008) \text { compared to Group } 3 .\end{array}$ \\
\hline & & & & $\begin{array}{l}\text { No significant difference } \\
\text { was found between Group } 2 \\
\text { and Group } 3 \text { on the BIT } \\
\text { pre-treatment to post-treatment. }\end{array}$ \\
\hline & & & & $\begin{array}{l}\text { Group } 1 \text { showed significant } \\
\text { improvement pre-treatment to } \\
\text { follow-up on the BIT }(\mathrm{p}=0.043) \text {. }\end{array}$ \\
\hline & & & & $\begin{array}{l}\text { There was no reported within- } \\
\text { group comparison of Group } 2 \\
\text { pre-treatment to follow-up. }\end{array}$ \\
\hline & & & & $\begin{array}{c}\text { There was no reported } \\
\text { within-group comparison of } \\
\text { Group } 3 \text { pre-treatment to follow-up. }\end{array}$ \\
\hline & & & & $\begin{array}{l}\text { There was no reported between } \\
\text {-group comparison of Group } 1 \\
\text { and Group } 2 \text { pre- } \\
\text { treatment to follow-up. }\end{array}$ \\
\hline & & & & $\begin{array}{c}\text { There was no reported } \\
\text { between-group comparison } \\
\text { of Group } 1 \text { and Group } 3 \text { pre-treatment to follow-up. }\end{array}$ \\
\hline & & & & $\begin{array}{l}\text { There was no reported between- } \\
\text { group comparison of Group } 2 \text { and Group } 3 \text { pre-treatment to follow-up. }\end{array}$ \\
\hline $\begin{array}{l}\text { Ianes et al. } \\
\quad[20]\end{array}$ & $\begin{array}{c}\mathrm{EL}=2 \\
\mathrm{MR}=8 / 10\end{array}$ & $\begin{array}{l}\text { Group } 2= \\
10 \text { partici- } \\
\text { pants }\end{array}$ & VST & $\begin{array}{c}\text { Group } 1 \text { showed significant } \\
\text { improvement pre-treatment to } \\
\text { post-treatment on the Bells test } \\
(\mathrm{p}=0.017) \text {, line bisection }(\mathrm{p}=0.011) \\
\text { and line crossing }(\mathrm{p}=0.012)\end{array}$ \\
\hline
\end{tabular}




\section{Open Access Journal of Neurology \& Neurosurgery}

\begin{tabular}{|c|c|c|c|c|}
\hline & & $\begin{array}{l}\text { Group } 1 \\
\quad=10 \\
\text { participants }\end{array}$ & $\begin{array}{l}\text { Right half } \\
\text {-Field } \\
\text { patch }\end{array}$ & $\begin{array}{l}\text { Group } 2 \text { showed significant improvement } \\
\text { pre-treatment to post-treatment on } \\
\text { the Bells test }(p=0.005) \text {, line bisection } \\
(p=0.007) \text {, and line crossing }(p=0.008)\end{array}$ \\
\hline & & & & $\begin{array}{l}\text { No significant difference was } \\
\text { found between Group } 1 \text { and } \\
\text { Group } 2 \text { on the Bells test, line bisection, } \\
\text { or line crossing pre-treatment to } \\
\text { post-treatment. }\end{array}$ \\
\hline & & & & $\begin{array}{c}\text { Group 1 showed significant } \\
\text { improvement pre-treatment to } \\
\text { follow-up on the Bells test }(\mathrm{p}=0.018) \\
\text { line bisection }(\mathrm{p}=0.011) \text {, and line crossing }(\mathrm{p}=0.012) \text {. }\end{array}$ \\
\hline & & & & $\begin{array}{l}\text { Group } 2 \text { showed significant improvement } \\
\text { pre-treatment to follow-up on the } \\
\text { Bells test }(p=0.005) \text {, line bisection ( } p=0.007) \text {, and line crossing }(p=0.005) \text {. }\end{array}$ \\
\hline & & & & $\begin{array}{l}\text { Group } 2 \text { showed significantly greater improvement } \\
\text { pre-treatment to follow-up on line crossing } \\
\text { (p = 0.044) compared to Group } 1 . \\
\text { No significant difference was found } \\
\text { between Group } 1 \text { and Group } 2 \text { on the Bells test or } \\
\text { on-line bisection pre-treatment to follow-up. }\end{array}$ \\
\hline \multirow[t]{6}{*}{$\begin{array}{l}\text { Kerkhoff, et } \\
\text { al. [21] }\end{array}$} & $\begin{array}{c}E L=2 \\
M R=8 / 10\end{array}$ & $\begin{array}{l}\text { Group } 2= \\
12 \text { partici- } \\
\text { pants }\end{array}$ & VST & $\begin{array}{l}\text { Group } 1 \text { showed significant improvement } \\
\text { pre-treatment to post-treatment on the } \\
\text { FNI }(\mathrm{p}=0.041) \text {. Group } 1 \text { showed no significant } \\
\text { improvement pre-treatment to post-treatment on the UBNI. }\end{array}$ \\
\hline & & $\begin{array}{l}\text { Group } 1 \\
\quad=12 \\
\text { participants }\end{array}$ & $\begin{array}{l}\text { Smooth PUR- } \\
\text { SUIT Training }\end{array}$ & $\begin{array}{l}\text { Group } 2 \text { showed significant improvement } \\
\text { pre-treatment to post-treatment on the } \\
\text { FNI }(\mathrm{p}<0.001) \text { and on the UBNI }(\mathrm{p}=0.001) \text {. }\end{array}$ \\
\hline & & & & $\begin{array}{l}\text { There was no reported between- } \\
\text { group comparison of } \\
\text { Group } 1 \text { and Group } 2 \text { pre-treatment to post-treatment. }\end{array}$ \\
\hline & & & & $\begin{array}{l}\text { Group 1 showed significant improvement } \\
\text { pre-treatment to follow-up on the FNI } \\
(\mathrm{p}=0.010) \text {. Group } 1 \text { showed } \\
\text { no significant improvement pre-treatment to follow-up on the UBNI. }\end{array}$ \\
\hline & & & & $\begin{array}{l}\text { Group } 2 \text { showed significant } \\
\text { improvement pre-treatment } \\
\text { to follow-up on the FNI }(\mathrm{p}<0.001) \text { and on the UBNI }(\mathrm{p}<0.002) \text {. }\end{array}$ \\
\hline & & & & $\begin{array}{c}\text { There was no reported } \\
\text { between-group comparison of } \\
\text { Group } 1 \text { and Group } 2 \text { pre-treatment to follow-up. }\end{array}$ \\
\hline \multirow[t]{3}{*}{$\begin{array}{l}\text { Kerkhoff et } \\
\text { al. [22] }\end{array}$} & $\begin{array}{c}E L=2 \\
M R=6 / 10\end{array}$ & $\begin{array}{l}\text { Group } 1 \\
\quad=21 \\
\text { participants }\end{array}$ & VST & $\begin{array}{l}\text { Group } 1 \text { showed no significant improvement } \\
\text { pre-treatment to post-treatment on perceptual } \\
\text { line bisection, motor line bisection, right-sided } \\
\text { single-digit numeral cancellation, right-sided double-digit } \\
\text { numeral cancellation, left-sided single-digit numeral } \\
\text { cancellation, left-sided double-digit numeral } \\
\text { cancellation, or paragraph reading. }\end{array}$ \\
\hline & & $\begin{array}{l}\text { Group } 2 \\
\quad=24 \\
\text { participants }\end{array}$ & $\begin{array}{l}\text { Smooth PUR- } \\
\text { SUIT Training }\end{array}$ & $\begin{array}{c}\text { Group } 2 \text { showed significant improvement } \\
\text { pre-treatment to post-treatment on } \\
\text { perceptual line bisection }(\mathrm{p}=0.006) \\
\text { motor line bisection }(\mathrm{p}=0.001) \text {, right-sided single-digit numeral } \\
\text { cancellation }(\mathrm{p}=0.004) \text {, right-sided double-digit } \\
\text { numeral cancellation }(\mathrm{p}=0.002) \text {, left-sided } \\
\text { single-digit numeral cancellation }(\mathrm{p}<0.001) \\
\text { left-sided double-digit numeral cancellation }(\mathrm{p}<0.001) \\
\text { and paragraph reading }(\mathrm{p}<0.001)\end{array}$ \\
\hline & & & & $\begin{array}{l}\text { There was no reported between- } \\
\text { group comparison of Group } 1 \\
\text { and Group } 2 \text { pre-treatment } \\
\text { to post-treatment. }\end{array}$ \\
\hline
\end{tabular}




\begin{tabular}{|c|c|c|c|c|}
\hline & & & & $\begin{array}{l}\text { There was no reported within- } \\
\text { group comparison of Group } 1 \\
\text { pre-treatment to follow-up. }\end{array}$ \\
\hline & & & & $\begin{array}{c}\text { Group } 2 \text { showed significant improvement } \\
\text { pre-treatment to follow-up on perceptual } \\
\text { line bisection }(\mathrm{p}=0.004) \text {, motor line bisection } \\
(\mathrm{p}=0.001) \text {, right-sided single-digit numeral } \\
\text { cancellation }(\mathrm{p}=0.003) \text {, right-sided double-digit numeral cancellation }(\mathrm{p}=0.007) \text {, } \\
\text { left-sided single-digit numeral cancellation }(\mathrm{p}<0.001) \text {, left-sided double-digit numeral } \\
\text { cancellation }(\mathrm{p}<0.001) \text {, and paragraph reading }(\mathrm{p}<0.001) \text {. }\end{array}$ \\
\hline & & & & $\begin{array}{l}\text { There was no reported between- } \\
\text { group comparison of Group } 1 \text { and } \\
\text { Group } 2 \text { pre-treatment to follow-up. }\end{array}$ \\
\hline \multirow[t]{6}{*}{$\begin{array}{l}\text { Kerkhoff, et } \\
\text { al. [23] }\end{array}$} & $\begin{array}{c}E L=2 \\
M R=7 / 10\end{array}$ & $\begin{array}{l}\text { Group 1 = } 3 \\
\text { participants }\end{array}$ & VST & $\begin{array}{l}\text { Group } 1 \text { showed significant improvement } \\
\text { pre-treatment to post-treatment on line } \\
\text { bisection }(\mathrm{p}<0.007) \text {. Group } 1 \text { showed } \\
\text { no significant improvement pre-treatment } \\
\text { to post-treatment on numeral cancellation } \\
\text { or on paragraph reading. }\end{array}$ \\
\hline & & $\begin{array}{l}\text { Group } 2=3 \\
\text { participants }\end{array}$ & $\begin{array}{l}\text { Optokinetic } \\
\text { Stimulation } \\
\text { Training }\end{array}$ & $\begin{array}{c}\text { Group } 2 \text { showed significant } \\
\text { improvement pre-treatment to } \\
\text { post-treatment on line bisection } \\
(\mathrm{p}<0.0008) \text {, numeral cancellation } \\
(\mathrm{p}<0.008) \text {, and paragraph reading }(\mathrm{p}<0.007) \text {. }\end{array}$ \\
\hline & & & & $\begin{array}{c}\text { Group } 2 \text { showed significantly } \\
\text { greater improvement pre-treatment } \\
\text { to post-treatment on line bisection } \\
(\mathrm{p}<0.0001) \text {, numeral cancellation }(\mathrm{p}<0.001) \\
\text { and paragraph reading }(\mathrm{p}<0.001) \text { compared to Group } 1 .\end{array}$ \\
\hline & & & & $\begin{array}{l}\text { There was no reported within } \\
\text {-group comparison of Group } 1 \\
\text { pre-treatment to follow-up. }\end{array}$ \\
\hline & & & & $\begin{array}{c}\text { There was no reported } \\
\text { within-group comparison of } \\
\text { Group } 2 \text { pre-treatment to follow-up. }\end{array}$ \\
\hline & & & & $\begin{array}{l}\text { There was no reported } \\
\text { between-group comparison } \\
\text { of Group } 1 \text { and Group } 2 \text { pre- } \\
\text { treatment to follow-up. }\end{array}$ \\
\hline \multirow[t]{5}{*}{$\begin{array}{l}\text { Luukkain- } \\
\text { en-Markkula, } \\
\text { et al. [24] }\end{array}$} & $\begin{array}{c}E L=2 \\
M R=7 / 10\end{array}$ & $\begin{array}{l}\text { Group } 1=6 \\
\text { participants }\end{array}$ & VST & $\begin{array}{l}\text { Group } 1 \text { showed no significant } \\
\text { improvement pre-treatment to } \\
\text { post-treatment on the BIT or on the CBS. }\end{array}$ \\
\hline & & $\begin{array}{l}\text { Group } 2=6 \\
\text { participants }\end{array}$ & $\begin{array}{l}\text { Arm Activa- } \\
\text { tion } \\
\text { Training }\end{array}$ & $\begin{array}{l}\text { Group } 2 \text { showed significant } \\
\text { improvement pre-treatment to } \\
\text { post-treatment on the BIT ( } \mathrm{p}=0.031 \text { ). } \\
\text { Group } 2 \text { showed no significant } \\
\text { improvement pre-treatment to } \\
\text { post-treatment on the CBS. }\end{array}$ \\
\hline & & & & $\begin{array}{l}\text { There was no reported } \\
\text { between-group comparison } \\
\text { of Group } 1 \text { and Group } 2 \text { pre- } \\
\text { treatment to post-treatment. }\end{array}$ \\
\hline & & & & $\begin{array}{l}\text { Group } 1 \text { showed significant } \\
\text { improvement pre-treatment to } \\
\text { follow-up on the BIT }(\mathrm{p}=0.031) \text {. } \\
\text { Group } 1 \text { showed no significant } \\
\text { improvement pre-treatment to follow-up on the CBS. }\end{array}$ \\
\hline & & & & $\begin{array}{l}\text { Group } 2 \text { showed significant } \\
\text { improvement pre-treatment to } \\
\text { follow-up on the BIT ( } \mathrm{p}=0.031 \text { ). } \\
\text { Group } 2 \text { showed no significant } \\
\text { improvement pre-treatment to } \\
\text { follow-up on the CBS. }\end{array}$ \\
\hline
\end{tabular}




\begin{tabular}{|c|c|c|c|c|}
\hline & & & & $\begin{array}{l}\text { There was no reported } \\
\text { between-group comparison of } \\
\text { Group } 1 \text { and Group } 2 \text { pre- } \\
\text { treatment to follow-up. }\end{array}$ \\
\hline & & & & $\begin{array}{l}\text { Group } 2 \text { showed significant } \\
\text { improvement pre-treatment } \\
\text { to follow-up on the BIT }(\mathrm{p}=0.031) \text {. } \\
\text { Group } 2 \text { showed no significant } \\
\text { improvement pre-treatment to } \\
\text { follow-up on the CBS. }\end{array}$ \\
\hline & & & & $\begin{array}{l}\text { There was no reported } \\
\text { between-group comparison } \\
\text { of Group } 1 \text { and Group } 2 \\
\text { pre-treatment to follow-up. }\end{array}$ \\
\hline \multirow[t]{4}{*}{$\begin{array}{l}\text { Weinberg et } \\
\text { al. [12] }\end{array}$} & $\begin{array}{c}E L=2 \\
M R=7 / 10\end{array}$ & $\begin{array}{l}\text { Group } 1 \\
\quad=25 \\
\text { participants }\end{array}$ & VST & $\begin{array}{c}\text { Group 1 showed significant } \\
\text { improvement in individuals with } \\
\text { severe brain damage pre-treatment } \\
\text { to post-treatment on the WRAT }(\mathrm{p}=0.01) \text {, } \\
\text { copying }(\mathrm{p}=0.01) \text {, paragraph reading }(\mathrm{p}=0.01) \text {, } \\
\text { and performing simple arithmetic }(\mathrm{p}=0.01) \text {. } \\
\text { Group } 1 \text { showed significant improvement } \\
\text { in individuals with mild brain damage } \\
\text { pre-treatment to post-treatment on the } \\
\text { WRAT }(\mathrm{p}=0.05) \text {. Group } 1 \text { showed no } \\
\text { significant improvement pre-treatment } \\
\text { to post-treatment on copying, paragraph } \\
\text { reading, or performing simple arithmetic. }\end{array}$ \\
\hline & & $\begin{array}{l}\text { Group } 2 \\
\quad=32 \\
\text { participants }\end{array}$ & Control & \\
\hline & & & & $\begin{array}{l}\text { Group } 2 \text { showed no } \\
\text { significant improvement } \\
\text { in individuals with severe } \\
\text { or mild brain damage } \\
\text { pre-treatment to post-treatment } \\
\text { on the WRAT, copying, } \\
\text { paragraph reading, or } \\
\text { performing simple arithmetic. }\end{array}$ \\
\hline & & & & $\begin{array}{l}\text { There was no reported } \\
\text { between-group comparison of Group } 1 \text { and Group } 2 \text { pre-treatment to } \\
\text { post-treatment. }\end{array}$ \\
\hline
\end{tabular}

$\mathrm{EL}$ = Evidence Level; MR = Methodological Rigor; VST = Visual Scanning Training; BIT = Behavioral Inattention Test; CBS = Catherine Bergego Scale; FNI = Functional Neglect Index; UBNI = Unawareness and Behavioral Neglect Index; WRAT = Wide Range Achievement Test.

Luukkainen-Markkula et al. [24] examined 12 participants with left neglect caused by a right-sided CVA and randomized them into two groups. Group one consisted of six participants who received VST, and group two consisted of six participants who received arm activation training. Group one followed a three-week protocol (10 to 12 hours of treatment) that included three different visual scanning tasks, and group two followed a three-week protocol (20 to 30 hours of treatment) that included active, active-assisted, and/or passive left arm activation. Both groups underwent evaluations pre-treatment, post-treatment, and six months following treatment. Neglect outcomes were measured by the BIT [25] and the CBS [26] as previously discussed in the Chan and Man [18] study. The results of this study can be found in Table 5 .

Weinberg et al. [12] examined 57 participants with left neglect caused by a right-sided CVA and randomized them into two groups. Group one consisted of 25 participants who received VST, and group two consisted of 32 participants who received conventional therapy and served as the control group. Group one followed a four-week protocol (20 one-hour sessions) that included reading, writing, and arithmetic tasks; and this group underwent evaluations pre-treatment and posttreatment. Group two underwent a baseline evaluation and an evaluation one month later. Neglect outcomes were measured by the Wide Range Achievement Test (WRAT), copying, paragraph reading, and performing simple arithmetic. The WRAT [28] is an instrument that measures reading, writing, and arithmetic skills. The copying activity is similar to one of the behavioral items contained in the BIT [25]. Paragraph reading is an activity contained in the Gray Oral Reading Test [29]. Performing simple arithmetic is an activity contained in the Metropolitan Achievement Test [30]. The results of this study can be found in Table 5. 


\section{Discussion}

The purpose of this systematic review was to evaluate the effectiveness of VST at reducing the effects of left neglect caused by a right-sided CVA. Eight articles [12,18-24] were found to be eligible and were used in this systematic review.

Three of the eight studies [12,18-19] compared a VST group with a control group. Two of these studies $[12,18]$ included a control group that received conventional therapy, and the control group of the other study received no treatment [19]. The results of all three studies [12,18-19] indicated that the use of VST with conventional therapy was better than the provision of no treatment or the use of conventional therapy alone. VST may have been effective because of the way in which the intervention was performed. Although pacing was not specifically addressed in the Chan and Man [18] study or in the Ferriera et al. [19] study, the other four intervention components recommended by Diller and Weinberg [11] (a relevant task that encourages head movements, anchoring, density, and feedback) were present in all three studies. [12,18-19] In addition to comparing a VST group with a control group that received no treatment, Ferriera et al. [19] found that VST was better at reducing the effects of left neglect than was mental practice training. The VST group in this study also demonstrated long-term functional improvements.

Five of the eight studies [20-24] compared VST with interventions such as a right half-field patch, smooth pursuit training, optokinetic stimulation training, and arm activation training. In all five studies, VST was found to be generally less effective at reducing left neglect when compared to these other interventions. A couple of factors may have accounted for the poorer outcomes associated with VST. First, three of the studies [21-23] did not provide participants with a relevant task that encouraged them to rotate their head and neck in the direction of their neglect as was recommended by Diller and Weinberg [11]. Instead, the participants visualized static stimuli on a computer screen, and head movements were discouraged. Second, the duration of the treatments may have negatively impacted the effect of VST in the other two studies. [20,24] In the Ianes et al. [20] study, participants in a right half-field patch group received a total of 120 hours of treatment as compared to 10 hours of treatment for the VST group. In the Luukkainen-Markkula et al. [24] study, participants in an arm activation training group received a total of 20 to 30 hours of treatment as compared to 10 to 12 hours of treatment for the VST group. Therefore, the VST group received less total treatment time than did the other intervention group. In addition, literature suggests that at least 20 [31] to 40 [32] hours of VST is the most effective treatment duration. Although VST was generally less effective at reducing left neglect when compared to several other interventions, [2024] participants who received VST still demonstrated statistically significant improvements.

Three additional randomized controlled trials [33-35] found VST to be even more effective at reducing the effects of left neglect when it was combined with other interventions. Wiart et al. [33] randomly assigned 11 individuals with CVA-related neglect to an experimental group and 11 similar individuals to a control group. The experimental group received VST, trunk rotation training, and conventional therapy; whereas the control group received conventional therapy only. The experimental group demonstrated significantly greater improvements than did the control group according to three neglect outcome measures. The effectiveness of the concurrent use of VST and trunk rotation training may have been due to "a synergistic effect between axial rotation of the trunk, generating specific motor, vestibular, and cerebellar activation, and classic exploratory reconditioning that preferentially activates the cognitive and visual systems" [33]. (p428) Polanowska et al. [34] randomly assigned 20 individuals with CVA-related neglect to an experimental group and 20 similar individuals to a control group. The experimental group received VST and real electro-stimulation of the left hand, whereas the control group received VST and sham electro-stimulation of the left hand. The experimental group demonstrated significantly greater improvements than did the control group according to three neglect outcome measures. The effectiveness of the concurrent use of VST and left-hand electro-stimulation may have been due to "an increase in the activation level in [the parietal region], which is crucial for spatial attention" [34]. (p377) VanWyk et al. [35] randomly assigned 12 individuals with CVA-related neglect to an experimental group and 12 similar individuals to a control group. The experimental group received VST, saccadic eye movement training, and conventional therapy; whereas the control group received conventional therapy only. The experimental group demonstrated significantly greater improvements than did the control group according to two neglect outcome measures. The effectiveness of the concurrent use of VST and saccadic eye movement training may have been due to "[a positive] effect on the visual perceptual processing of participants that present with [unilateral spatial neglect] poststroke" [35] (871).

\section{Strengths and Limitations of the Systematic Review}

The primary strengths of the systematic review included the following:

a. all eight studies [12,18-24] had an evidence level of 2 (Table 3);

b. all eight studies [12,18-24] had a methodological rigor of $6 / 10$ or greater (Table 4 ); and

c. the studies[12, 18-24] were individually assessed by all five authors, thus reducing the risk of bias.

The primary limitations of the systematic review included the following:

a. three of the studies $[21,23]$ in which VST was generally less effective than another intervention did not provide participants with a relevant task that encouraged them to 
rotate their head and neck in the direction of their neglect;

b. two of the studies $[20,24]$ in which VST was generally less effective than another intervention did not provide participants with a total treatment time of at least 20 to 40 hours;

c. there was wide variability in the VST frequency, VST duration, VST protocols, and neglect outcome measures used in the eight studies; [12, 18-24]

d. only four of the eight studies[19-21, 24] reported longterm follow-up results; and

e. because this systematic review only included studies published in English, there was the potential that a language bias was created.

\section{Implications for Clinical Practice and Future Research}

This systematic review revealed that VST is generally an effective intervention for reducing the effects of left neglect, especially when it is performed as originally intended (providing a relevant task that encourages head movements and incorporating anchoring, density, pacing, and feedback into the intervention). In addition, therapists should keep in mind that the positive impacts of VST may not be apparent until the intervention has been delivered over a prolonged period of time. The effectiveness of VST also appears to be enhanced when it is used in combination with conventional therapy or with other interventions such as trunk rotation training, left-hand electrostimulation, or saccadic eye movement training.

Future research should focus on the standardization of VST protocols, including the frequency and duration of the treatment sessions. Studies should also attempt to determine which outcome measures best evaluate the effectiveness of VST on CVA-related neglect. In addition, the long-term impact of VST needs to be further examined; and the follow-up results should include the effect VST has on functional outcome measures, not just on neglect outcome measures.

\section{Conclusion}

CVAs have affected over 7 million individuals in the United States alone, and almost 800,000 Americans experience a CVA on an annual basis [2]. One of the most common cognitive issues associated with a CVA is an attention deficit known as hemispatial neglect $[1,6]$. Once neglect has been diagnosed, therapists have a number of different interventions from which to choose $[6,8]$. One of the earliest interventions still in use today is VST [8]. Three of the eight studies in this systematic review [12,18-19]. indicated that the use of VST with conventional therapy was better than the provision of no treatment or the use of conventional therapy alone. In addition, one study [19] found that VST was better at reducing the effects of left neglect than was mental practice training. Although VST was generally less effective at reducing left neglect when compared to several other interventions, [20-24] participants who received VST still demonstrated statistically significant improvements. Therefore, VST is an acceptable option when treating individuals with left neglect caused by a right-sided CVA.

\section{References}

1. Mark VW (2016) Stroke and behavior. Neurol clin 34(1): 205-234.

2. Benjamin EJ, Virani SS, Callaway CW, Chamberlain AM, Chang AR, et al. (2018) Heart disease and stroke statistics - 2018 update: a report from the American Heart Association. Circulation 137(12): e67-e492.

3. (2018) Centers for Disease Control and Prevention. Family history and other characteristics that increase risk for stroke.

4. (2017) Centers for Disease Control and Prevention. Stroke facts. Centers for Disease Control and Prevention.

5. (2018) Centers for Disease Control and Prevention. Types of stroke. Centers for Disease Control and Prevention.

6. Corbetta M (2014) Hemispatial neglect: clinic, pathogenesis, and treatment. Semin Neurol 34(5): 514-523.

7. Husain M, Rorden C (2003) Non-spatially lateralized mechanisms in hemispatial neglect. Nat Rev Neurosci 4(1): 26-36.

8. Husain M (2008) Hemi spatial neglect In: Goldenberg G, Miller BL (Eds.), Handbook of Clinical Neurology, 88: Elsevier, Amsterdam, Netherlands, pp. 359-372.

9. Azouvi P, Samuel C, Louis-Dreyfus A, Bernati T, Bartolomeo P, et al. (2002) Sensitivity of clinical and behavioral tests of spatial neglect after right hemisphere stroke. J Neurol Neurosurg Psychiatry 73(2): 160-166.

10. Malhotra PA, Greenwood R, Husain M (2004) The diagnosis of spatial neglect in acute stroke. J Neurol Neurosurg Psychiatry 75(3): 521.

11. Diller L, Weinberg J (1977) Hemi-inattention in rehabilitation: the evolution of a rational remediation program. In: Weinstein EA, Friedland RP (Eds.), Advances in Neurology 18: Raven Press, New York, USA, p. 63-82.

12. Weinberg J, Diller L, Gordon WA, Gerstman LJ, Lieberman A, et al. (1977) Visual scanning training effect on reading-related tasks in acquired right brain damage. Arch Phys Med Rehabil 58(11): 479-486.

13. Luaute J, Halligan P, Rode G, Rossetti Y, Boisson D (2006) Visuo-spatial neglect: a systematic review of current interventions and their effectiveness. Neurosci Biobehav Rev 30(7): 961-982.

14. Klinke ME, Hafsteinsdottir TB, Hjaltason H, Jonsdottir H (2015) Wardbased interventions for patients with hemispatial neglect in stroke rehabilitation: a systematic literature review. Int J Nurs Stud 52(8):13751403.

15. (2016) Centre for Evidence-Based Medicine. Oxford Centre for Evidence-Based Medicine 2011 levels of evidence. Centre for Evidence-Based Medicine.

16. (1999) Physiotherapy Evidence Database. PED ro scale. Physiotherapy Evidence Database.

17. Moher D, Liberati A, Tetzlaff J, Altman DG (2009) Preferred reporting items for systematic reviews and meta-analyses: the PRISMA statement. PLoS Med 6(7): e1000097.

18. Chan DYW, Man DWK (2013) Unilateral neglect in stroke: a comparative study. Top Geriatr Rehabil 29(2): 126-134.

19. Ferreira HP, Lopes MAL, Luiz RR, Cardoso L, Andre C (2011) Is visual scanning better than mental practice in hemispatial neglect? Results from a pilot study. Top Stroke Rehabil 18(2):155-161. 
20. Ianes P, Varalta V, Gandolfi M, Picelli A, Corno M, et al. (2012) Stimulating visual exploration of the neglected space in the early stage of stroke by hemifield eye-patching: a randomized controlled trial in patients with right brain damage. Eur J Phys Rehabil Med 48(2): 189-196.

21. Kerkhoff G, Bucher L, Brasse M, Leonhart E, Holzgraefe M, et al. (2014) Smooth pursuit bedside training reduces disability and unawareness during the activities of daily living in neglect: a randomized controlled trial. Neurorehabil Neural Repair 28(6): 554-563.

22. Kerkhoff G, Reinhart S, Ziegler W, Artinger F, Marquardt C, et al. (2013) Smooth pursuit eye movement training promotes recovery from auditory and visual neglect: a randomized controlled study. Neurorehabil Neural Repair 27(9): 789-798.

23. Kerkhoff G, Keller I, Artinger F, Hildebrandt H, Marquardt C, et al (2012) Recovery from auditory and visual neglect after optokinetic stimulation with pursuit eye movements-transient modulation and enduring treatment effects. Neuropsychologia 50(6):1164-1177.

24. Luukkainen-Markkula R, Tarkka IM, Pitkanen K, Sivenius J, Hamalainen H (2009) Rehabilitation of hemispatial neglect: a randomized study using either arm activation or visual scanning training. Restor Neuro Neurosci 27(6): 663-672.

25. Wilson B, Cockburn J, Halligan P (1987) Development of a behavioral-test of visuospatial neglect. Arch Phys Med Rehabil 68(2): 98-102.

26. Azouvi B, Marchal F, Samuel C, Morin L, Renard C, et al. (1996) Functional consequences and awareness of unilateral neglect: study of an evaluation scale. Neuropsychological Rehabilitation 6(2): 133-150.
27. Gauthier L, Dehaut F, Joanette Y (1989) The Bells Test- a quantitative and qualitative test for visual neglect. International Journal of Clinical Neuropsychology 11(2): 49-54.

28. Jastak J (1946) Wide Range Achievement Test. Guidance Associates of Delaware, Wilmington, Delaware, USA.

29. Gray WS, Robinson HM (1967) Gray Oral Reading Test. Bobb-Merrill, Indianapolis, Indiana, USA.

30. Prescott GA, Balow IH, Hogan TP, Farr RC (1978) Metropolitan Achievement Tests. The Psychological Corporation, New York, USA.

31. Shinsha N, Ishigami S (1999) Rehabilitation approach to patients with unilateral spatial neglect. Top Stroke Rehabil 6(1): 1-14.

32. Pizzamiglio L, Antonucci G, Judica A, Montenero P, Razzano C, et al. (1992) Cognitive rehabilitation of the hemineglect disorder in chronic-patients with unilateral right brain-damage. J Clin Exp Neuropsychol 14(6): 901-923.

33. Wiart L, Côme AB, Debelleix X, Petit H, Joseph PA, et al. (1997) Unilateral neglect syndrome rehabilitation by trunk rotation and scanning training. Arch Phys Med Rehabil 78(4): 424-429.

34. Polanowska K, Seniow J, Paprot E, Lesniak M, Czlonkowska A (2009) l. Neuropsychol Rehabil 19(3): 364-382.

35. Van Wyk A, Eksteen CA, Rheeder P (2014) The effect of visual scanning exercises integrated into physiotherapy I patients with unilateral spatial neglect poststroke: a matched-pair randomized control trial. Neurorehabil Neural Repair 28(9): 856-873.

\section{Your next submission with Juniper Publishers will reach you the below assets}

- Quality Editorial service

- Swift Peer Review

- Reprints availability

- E-prints Service

- Manuscript Podcast for convenient understanding

- Global attainment for your research

- Manuscript accessibility in different formats

( Pdf, E-pub, Full Text, Audio)

- Unceasing customer service

Track the below URL for one-step submission

https://juniperpublishers.com/online-submission.php 